VIU, M.A.O. et al. Diarreia viral bovina: revisão. PUBVET, Londrina, V. 8, N. 3, Ed. 252, Art. 1670, Fevereiro, 2014.

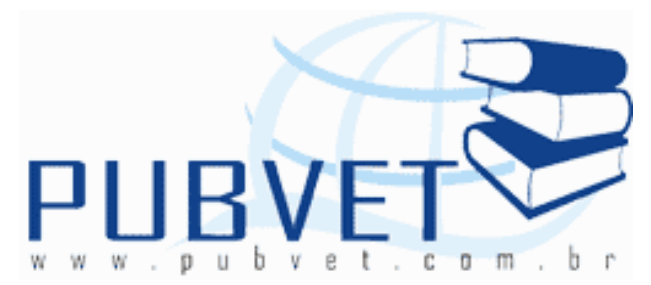

PUBVET, Publicações em Medicina Veterinária e Zootecnia.

\title{
Diarreia viral bovina: revisão
}

Marco Antônio de Oliveira Viu' ${ }^{1}$, Luzia Renata Oliveira Dias ${ }^{2}$, Dyomar Toledo Lopes $^{1}$, Alessandra Feijó Marcondes Viu ${ }^{1}$, Henrique Trevizoli Ferraz ${ }^{1}$

${ }^{1}$ Professores da Universidade Federal de Goiás - UFG.

E-mail: marcoviu@yahoo.com.br

${ }^{2}$ Médica Veterinária Residente do Laboratório de Fisiopatologia da Reprodução Animal, UFG/CAJ

\section{Resumo}

A diarreia viral bovina (BVD) é uma enfermidade de grande impacto econômico, endêmica na maioria dos países e causadora de perdas produtivas e reprodutivas. No Brasil, a doença está amplamente disseminada nos rebanhos bovinos. A infecção ocorre na maioria dos biungulados, mas a predominância é em bovinos. Esta revisão objetiva apontar características relevantes da BVD abrangendo sua etiologia, epidemiologia, patogenia, sintomas, diagnóstico, prognóstico, terapêutica e controle.

Palavras-chave: abortos, BVD, reprodução, sanidade

\section{Bovine viral diarrhea: review}

\section{Abstract}

The bovine viral diarrhea (BVD) is a disease of major negative economic impact, endemic in most countries and causing productive and reproductive 
VIU, M.A.O. et al. Diarreia viral bovina: revisão. PUBVET, Londrina, V. 8, N. 3, Ed. 252, Art. 1670, Fevereiro, 2014.

losses. In Brazil, the disease is widespread in cattle herds. The infection occurs in most bi-ungulates, but the prevalence is in cattle. This review aims to point out relevant features of the BVD, covering its etiology, epidemiology, pathogenesis, symptoms, diagnosis, prognosis, treatment and control.

Keywords: abortions, BVD, reproduction, sanity

\section{INTRODUÇÃO}

A diarreia viral bovina (BVD) é uma enfermidade que, devido às perdas reprodutivas e de produção nos rebanhos do mundo todo, tem gerado grandes prejuízos econômicos. Além disso, a doença apresenta uma variedade de manifestações clínicas (TREMBLAY, 1996). A importância econômica dessa doença quanto a essas perdas pode ser diretamente observada através da queda na produção de leite, decréscimo na taxa de concepção, abortamento, mumificação fetal, nascimento de bezerros fracos e aumento da taxa de mortalidade neonatal (DUBOVI, 1994).

Segundo PERDRIZET et al. (1987), o vírus da BVD está associado a problemas reprodutivos, entéricos e respiratórios.

Desde a década de 60, estudos comprovaram a existência de dois genótipos do vírus no território brasileiro (LEMOS, 1998; CANAL et al., 1998; GIL, 1998).

Esta revisão objetiva apontar características relevantes da BVD, abrangendo sua etiologia, epidemiologia, patogenia, sintomas, diagnóstico, prognóstico, terapêutica e controle.

\section{Etiologia}

O vírus da BVD (bovine viral diarrhea virus -BVDV) é o agente etiológico da BVD (RIDPATH, 2010). Trata-se de um RNA vírus, da família Flaviridae e gênero Pestivirus. Tem dois genótipos, o BVDV-1 e o BVDV-2, divididos em vários subgrupos, dos quais segundo XUE et al. (2008), 15 subgenótipos ( 1 a ao 10 ) pertencem ao BVDV-1 e 4 subgenótipos ( 2 a ao 2d) ao BVDV-2, apresentando dois biótipos, o citopatogênico e o não-citopatogênico, 
VIU, M.A.O. et al. Diarreia viral bovina: revisão. PUBVET, Londrina, V. 8, N. 3, Ed. 252, Art. 1670, Fevereiro, 2014.

onde variações antigênicas importantes foram encontradas, levando a diferentes classificações: tipo I, associado às formas clássicas da BVD, e tipo II, que possui maior patogenicidade (MOCKELIUNIENE et al., 2004; CANÁRIO et al., 2009).

De acordo com RADOSTITS et al. (2002), o tipo não-citopatogênico é o mais comum e mais importante, sendo que somente este atravessa a placenta, invade o feto e estabelece a infecção persistente no mesmo, sendo determinante para a disseminação do vírus. Além disso, o tipo nãocitopatogênico é a causa de doenças congênitas, entéricas e reprodutivas. Em contrapartida, o biótipo citopatogênico geralmente é associado com a doença da mucosa nos animais já persistentemente infectados (PI) com o nãocitopatogênico. No entanto, ambos biótipos podem ser isolados de animais que estejam morrendo da doença da mucosa, sendo que há evidência de que o citopatogênico surge por mutação do não-citopatogênico nos animais PI.

Todos Flaviviridaes são vírus esféricos com 40 a 50 nm de diâmetro. A partícula viral é constituída por envelope lipídico exterior circundando um reservatório interno de proteína ou da cápside que contém o genoma viral. O envelope lipídico, o qual é derivado das membranas da célula hospedeira infectada, torna o vírus susceptível à inativação por solventes e detergentes. 0 peso molecular do vírion BVDV foi estimado como $6,0 \times 10^{7}$ e a densidade de flutuação em sacarose é 1,10 a $1,15 \mathrm{~g} / \mathrm{cm}^{3}$ (RIDPATH, 2010).

O BVDV possui genoma constituído de RNA de cadeia positiva com cerca de 12.300 nucleotídeos que codificam uma grande poliproteína que é clivada em proteínas estruturais e não estruturais. A glicoproteína E2, o principal componente do vírion, é composto por cerca de 370 aminoácidos com massa molecular de $41 \mathrm{kDa}$. O terminal C da glicoproteína E2 inclui um domínio transmembranar de aproximadamente 30 aminoácidos, que ancora à membrana das células infectadas pelo vírus. A glicoproteína E2 é o maior alvo da resposta imune protetora contra a infecção provocada pelo BVDV (NELSON et al., 2012). 
VIU, M.A.O. et al. Diarreia viral bovina: revisão. PUBVET, Londrina, V. 8, N. 3, Ed. 252, Art. 1670, Fevereiro, 2014.

\section{Epidemiologia}

A BVD é endêmica na maioria dos países, com soroprevalência de 60 a 85\%, com 1 a 2\% de animais PI (HOUE, 1999; RADOSTITS et al., 2007). Estudos sorológicos demonstraram que o BVDV encontra-se amplamente difundido no rebanho bovino brasileiro, como o desenvolvido por MENDES et al. (2009) que realizaram levantamento em Minas Gerais e determinaram prevalência de $71,42 \%$ de animais reagentes para BVD.

No Rio Grande do Sul QUINCOZES et al. (2007) e FINGER et al. (2007) demonstraram prevalência do BVDV em $66,32 \%$ e $83 \%$ dos animais analisados, respectivamente. Já SILVA et al. (2009) detectaram 96,2\% de animais soropositivos para BVD no mesmo estado.

Na região sudeste do Brasil, DIAS \& SAMARA (2003) encontraram prevalência de $57,18 \%$ de animais soropositivos para BVD em rebanhos leiteiros.

BRITO et al. (2010), analisando a prevalência da infecção pelo BVDV no estado de Goiás, encontraram $64 \%$ de animais soropositivos.

A evidência do BVDV foi comprovada em muitos países. A forma predominante na natureza é o tipo 1 , já o tipo 2 é associado a uma patologia hemorrágica grave (GROOMS, 2006).

Embora ocorra a infecção na maioria dos biungulados, os bovinos são os hospedeiros primários da BVD. A doença pode acometer todas as idades, mas em geral ocorre entre seis e 24 meses. Após o nascimento, os bezerros são protegidos pelo colostro por três a seis meses de vida (OLIVEIRA, 2001; PETERHANS et al., 2010).

A eliminação do vírus da BVD ocorre pelas secreções e excreções de bovinos PI. Pode haver ainda transmissão através de insetos picadores, fômites e ruminantes silvestres (OLIVEIRA, 2001). Na transmissão transplacentária, ocorre infecção pelo biótipo não-citopatogênico, durante o primeiro trimestre de gestação, podendo gerar animais PI e imunotolerantes a este biótipo, tornando-se o principal fator na disseminação natural do vírus (TREMBLAY, 1996). 
VIU, M.A.O. et al. Diarreia viral bovina: revisão. PUBVET, Londrina, V. 8, N. 3, Ed. 252, Art. 1670, Fevereiro, 2014.

Produtos biológicos criopreservados como o sêmen e embriões constituem importante fonte de transmissão do vírus. O BVDV é eliminado no sêmen de touros PI e imunotolerantes, podendo ser transmitido a vacas soronegativas durante o processo de inseminação artificial. Além disso, o vírus pode estar presente no leite utilizado nos diluidores de sêmen (NOIVA, 2010). BIELANSKI et al. (2009) destacaram que a dose infectante mínima necessária para a transmissão via sêmen é de $25-50 \mathrm{TCID}_{50} / \mathrm{mL}$.

No gado bovino, a prevalência dos anticorpos antivirais varia entre países e entre regiões geográficas dentro do mesmo país (KAHN, 2007). A gravidade e a prevalência da doença em determinadas populações de animais são influenciadas por fatores ambientais, como a densidade da população, o tipo de exploração e as práticas de biossegurança (BROCK, 2004).

Diferenças consideráveis na prevalência de bovinos positivos ao anticorpo foram demonstradas em estudos sorológicos, variando de 70 a $80 \%$ (FLORES et al., 2005). Além disso, vários estudos mostraram que a predominância dos bovinos PI estaria entre 0,5\% e 2\% da população geral de bovinos (GUNN et al., 2004; GROOMS et al., 2006; KAHN, 2007).

Outros estudos realizados em tipos de criações e regiões geográficas distintas indicaram a predominância do vírus variando entre 40 e $90 \%$ nos rebanhos analisados (POLLETO et al., 2004; THOMPSON et al., 2006).

Em rebanhos individuais, a prevalência de bovinos PI pode chegar a valores superiores a $90 \%$ antes dos vitelos atingirem de 3 a 4 meses de idade se houver a prática normal da vacinação. A prevalência estimada de haver pelo menos um animal PI nos rebanhos está entre 10 a 50\% (HOUE, 1999; GROOMS et al., 2006; KAHN, 2007).

\section{Patogenia}

A infecção pelo BVDV é influenciada por alguns fatores como: hospedeiro imunocompetente ao vírus; idade do animal; infecção transplacentária e idade gestacional do feto; indução de tolerância imune no feto e o surgimento de competência imunofetal, aproximadamente em 180 
VIU, M.A.O. et al. Diarreia viral bovina: revisão. PUBVET, Londrina, V. 8, N. 3, Ed. 252, Art. 1670, Fevereiro, 2014.

dias de gestação; status imune; e presença de fatores estressantes (RADOSTITS et al., 2002; HIRSH \& ZEE, 2003).

Segundo RADOSTITS et al. (2002), quando a infecção fetal ocorre durante os três primeiros meses de gestação pode resultar no nascimento de bezerros vivos que são infectados persistentemente com o vírus da doença. Animais portadores eliminam o vírus na descarga nasal, no leite, na urina e na saliva. Ocorre então penetração do vírus no organismo pelas vias nasal e oral. A multiplicação se inicia nas células epiteliais das tonsilas e no tecido linfoide da boca e da faringe. Na sequência, o vírus atinge a corrente sanguínea (associada aos leucócitos) pelos vasos linfáticos. Muitas concentrações do vírus aparecem nas vias respiratórias, no baço, nos linfonodos e nas glândulas salivares (MARQUES, 2003). POTGIETER (2004) ressaltou que megacariócitos e linfócitos constituem importantes alvos do vírus, o qual induz necrose dessas células e prejudica a função daquelas que sobrevivem à infecção.

De acordo com KREY et al. (2006), o vírus, aderindo-se às célulasalvo, envolverá a interação das glicoproteínas E2 com glicosaminoglicanos e proteínas de membrana, respectivamente. Os receptores celulares do BVDV incluem o CD46 (proteína reguladora do complemento ou conjunto de diferenciação 46) e o receptor de lipoproteínas de baixa densidade (LDL-R). NOIVA (2010) destacou que a glicoproteína E2 é o componente mais imunogênico do vírus, induzindo a síntese de anticorpos neutralizantes. Além disso, o BVDV apresenta tropismo pelo ovário, testículo e sistema nervoso central. Ainda segundo este autor, a função das células apresentadoras de antígenos e a produção de interferon (IFN) são afetadas. Uma vez que ocorra a supressão parcial ou total de IFN em resposta à infecção pelo vírus nãocitopatogênico, permite-se o reconhecimento das proteínas virais como antígenos próprios, resultando na rejeição e destruição de linfócitos B e T antiBVDV durante a criação do sistema imune adaptativo. Sendo assim, GROMMS (2004) afirmou que os animais PI não apresentam anticorpos (neutralizantes ou não) contra o vírus persistente. No entanto, isso não impede que o animal PI apresente anticorpos anti-BVDV. 
VIU, M.A.O. et al. Diarreia viral bovina: revisão. PUBVET, Londrina, V. 8, N. 3, Ed. 252, Art. 1670, Fevereiro, 2014.

$\mathrm{Na}$ doença das mucosas o animal é exposto a um vírus antigenicamente diferente daquele ao qual foi exposto durante a vida fetal (CARTER, 2004; POTGIETER, 2004). Quando a mutação ocorre no animal PI com o vírus não-citopatogênico o número de vírus mutados (citopatogênicos) se expande, prevalecendo a existência dos dois biótipos no hospedeiro (GOENS, 2002).

Os casos graves de doença aguda por BVDV em bovinos infectados são causados por lesões no tecido epitelial gastrointestinal, tegumentar e do sistema respiratório (KAHN, 2007).

$\mathrm{Na}$ forma hiperaguda da doença observa-se os gânglios linfáticos aumentados de tamanho, erosões e ulcerações do trato gastrointestinal, hemorragias petequiais e equimóticas nas superfícies serosas das vísceras e depleção extensiva de linfócitos (RADOSTITS et al., 2002; KAHN, 2007).

\section{Sinais Clínicos}

Quando o animal se infecta pela forma intrauterina, em que a vaca prenhe, geralmente assintomática, é infectada por amostras do vírus da BVD não-citopatogênicas e de baixa patogenicidade, garantindo a infecção fetal sem a morte do mesmo, as manifestações irão aparecer somente dentro de semanas ou meses após a infecção da mãe. Os efeitos da infecção no feto irão depender da cepa e do estágio de desenvolvimento em que o mesmo se encontra. Entre 30-120 dias de gestação, infecções por cepas nãocitopatogênicas podem não ser letais e os bezerros se tornam imunotolerantes (PI). Esses animais suportam bem a presença do vírus em seus tecidos, mantendo altas concentrações viróticas na corrente sanguínea, que podem ser liberadas pelas secreções e excreções (HIRSCH \& FIGUEIREDO, 2006).

As formas da BVD causadas por amostras citopatogênicas em animais PI são: a aguda e a crônica das mucosas (DM), demonstrando serem fatais. A forma aguda é caracterizada por um período de incubação de 10 a 14 dias após a exposição, onde o animal apresentará febre bifásica (40-41ํㄷ), anorexia, taquicardia, polipneia, redução na produção leiteira, diarreia aquosa 
VIU, M.A.O. et al. Diarreia viral bovina: revisão. PUBVET, Londrina, V. 8, N. 3, Ed. 252, Art. 1670, Fevereiro, 2014.

profusa 2 a 3 dias após o início dos sinais clínicos, acidose, emaciação, desidratação, depressão e morte. Podem ocorrer lesões erosivas no epitélio da língua, palato e faringe (EVERMANN \& BARRINGTON, 2005; FLORES et al., 2005; GROOMS et al., 2006).

$\mathrm{Na}$ infecção crônica os sinais muitas vezes são inespecíficos, como redução no apetite, perda de peso, apatia seguida de enfraquecimento do animal, diarreia intermitente, timpanismo crônico, erosões interdigitais e lesões erosivas crônicas na mucosa oral e na pele não-cicatrizáveis. Corrimentos nasais e oculares persistentes também podem estar presentes. $\mathrm{Na}$ pele podem se desenvolver áreas de alopecia e hiperqueratinização, tipicamente na região do pescoço (FLORES et al., 2005; KAHN, 2007).

Animais que apresentam infecções assintomáticas desencadeiam um efeito imunossupressor, provocando enfermidades secundárias respiratórias, gastroentéricas e hemorrágicas. Quando o vírus é disseminado através da monta natural ou inseminação artificial podem ocorrer falhas reprodutivas, como falhas na fertilização, abortos, mumificação fetal, morte embrionária, nascimentos de bezerros fracos e inviáveis (GROOMS, 2006; GROOMS et al., 2006; OIE, 2008).

De acordo com KAHN (2007) e OIE (2008), as infecções agudas pelo BVDV podem causar a síndrome hemorrágica, sendo caracterizadas por trombocitopenia, diarreia sanguinolenta, hemorragias petequiais e equimóticas da conjuntiva, esclerótica e membrana nictitante, epistaxe, hemorragia nas superfícies mucosas da boca e vulva, hifema, pirexia $\left(41-42^{\circ} \mathrm{C}\right)$, desidratação, leucopenia e morte.

\section{Diagnóstico}

Segundo LAZZARI \& BARTHOLOMEI (2008), o diagnóstico deve ser baseado nos dados epidemiológicos, observações clínicas e isolamento do agente. HIRSH \& ZEE (2003) afirmaram que o isolamento do vírus pode ser feito através de secreções nasais, sangue, fezes, linfonodos e intestinos. 
VIU, M.A.O. et al. Diarreia viral bovina: revisão. PUBVET, Londrina, V. 8, N. 3, Ed. 252, Art. 1670, Fevereiro, 2014.

O BVDV é isolado por inoculação apropriada de amostras em culturas celulares. A reação da monocamada de imunoperoxidase é forma comum do isolamento viral e da detecção imunoenzimática do antígeno, sendo usada para uma rápida triagem do vírus (GROOMS et al., 2006). O antígeno viral pode ser também identificado em amostras de sangue através da técnica ELISA (FLORES et al., 2005).

A técnica de reação em cadeia da polimerase (PCR) é capaz de detectar porções de ácidos nucleicos virais de amostras sanguíneas e de tecidos, incluindo material conservado (RADOSTITS et al., 2002; KAHN, 2007).

\section{Diagnóstico diferencial}

A manifestação clínica da infecção estabelecerá o diagnóstico diferencial. Esta enfermidade pode ser diferenciada da febre aftosa (Aphthovirus), febre catarral maligna (Rhadinovirus), estomatite papulosa (Parapoxvirus), estomatite vesicular (família Rhabdoviridae), peste bovina (Morbillivirus), infecções por Adenovirus e disenteria bovina. Já em neonatos, o diagnóstico diferencial deve ser feito para rinotraqueíte infecciosa bovina sistêmica (GROOMS et al., 2006).

A febre catarral maligna e a peste bovina apresentam erosões bucais e diarreia, entretanto, a febre aftosa, estomatite vesicular, língua azul, estomatite papular bovina e estomatite necrótica apresentam lesões sem diarreia. Por outro lado, a salmonelose, disenteria invernal dos bovinos, doença de Johne, deficiência de cobre, coccidiose, intoxicação arsênica e ingurgitamento por carboidrato apresentam-se com diarreia e sem lesões orais (ANEXOS 1, 2, 3, 4) (RADOSTITS et al., 2002).

A diferenciação clínica do aborto causado pela BVD de outras causas de perdas fetais está demonstrada no anexo 5.

\section{Prognóstico e terapêutica}

Segundo GONDIM (2006), o prognóstico é reservado no início do surto, por não ser possível avaliar a morbidade. Quando existem lesões das 
VIU, M.A.O. et al. Diarreia viral bovina: revisão. PUBVET, Londrina, V. 8, N. 3, Ed. 252, Art. 1670, Fevereiro, 2014.

mucosas e desidratação, se torna desfavorável, pois a evolução é rápida e causa alta mortalidade.

Assim, o prognóstico é desfavorável em casos graves com diarreia aquosa profusa e lesões orais, podendo ser avaliado o abate do animal. Os animais com BVD crônica devem ser descartados e destruídos (RADOSTITS et al. 2002).

Em bovinos suspeitos de infecção aguda o tratamento se fundamenta no apoio e prevenção de infecção bacteriana secundária. São indicados agentes antimicrobianos de largo espectro, fluidoterapia, eletrolitos suplementares e vitaminas. Em bovinos com evidências clínicas de hemorragia devido à trombocitopenia pode-se efetuar transfusões de sangue total fresco, não devendo submeter estes animais a procedimentos cirúrgicos. Além disso, deve-se controlar a população de insetos para evitar lesões múltiplas que possam originar hemorragia (GROOMS et al., 2006; KAHN, 2007)

\section{Controle}

Medidas de controle e erradicação contra a BVD devem ser realizadas por um profissional responsável pela sanidade do rebanho, podendo constituir da vacinação de todo o lote de animais, deteç̧ão dos animais PI, seguida por eliminação destes e um adequado programa de biossegurança na propriedade (HIRSCH \& FIGUEIREDO, 2006).

Segundo RADOSTITS et al. (2002), a detecção e eliminação de animais PI são de fundamental importância para o programa de controle em explorações infectadas. Uma vez eliminados a disseminação do agente será diminuída e a saúde do rebanho melhorada. Uma das estratégias mais comuns para identificar animais PI é a colheita de amostras de soro de todos os animais do rebanho com idades superiores a 3 meses para isolamento do vírus.

A vacinação contra o BVDV deve ser utilizada para proteger animais da doença clínica, reduzir a circulação do vírus e para tentar impedir a infecção fetal, com consequente produção de vitelos PI. Assim, a vacinação de fêmeas 
VIU, M.A.O. et al. Diarreia viral bovina: revisão. PUBVET, Londrina, V. 8, N. 3, Ed. 252, Art. 1670, Fevereiro, 2014.

gestantes semanas antes do parto estimula a imunidade materna a fornecer proteção ao vitelo por imunidade passiva, especialmente nos dois primeiros trimestres, correspondendo ao período em que o feto está mais susceptível aos efeitos do vírus (FULTON, 2005). Contudo, ainda existem dúvidas se as vacinas existentes e os protocolos vacinais estão aptos a prevenir totalmente as infecções transplacentárias (LINDBERG et al., 2006). Está disponível no mercado a vacina CattleMaster GOLD FP $5 / L 5^{\circledR}$ (fabricada pela Fort Dodge Saúde Animal LTDA), sendo a primeira a conseguir aprovação do USDA (Departamento de Agricultura dos Estados Unidos) para proteção fetal contra a BVD (tipos 1 e 2) (FEED \& FOOD, 2012).

A vacinação de animais imunocompetentes que não têm infecções virais persistentes deve fornecer proteção parcial ou total contra infecções fetais, abortos, natimortos e atraso no crescimento intrauterino. A proteção contra a infecção fetal varia, aproximadamente, entre $60 \%$ a $100 \%$ (FULTON, 2005; GROOMS et al., 2006)

A seleção da vacina a ser utilizada em cada sistema de produção deve ser feita de acordo com as seguintes variáveis: resposta imunitária, reatividade cruzada, proteção fetal, duração da imunidade, imunossupressão, reversão da virulência, efeito dos anticorpos maternos na resposta imune e grau de pureza (KELLING, 2004).

Estão disponíveis no mercado nacional vacinas contendo vírus vivo modificado ou com vírus inativado. As vacinas vivas modificadas geralmente contêm estirpes citopatogênicos do vírus atenuado. Muitas das vacinas inativas possuem tanto estirpes citopatogênicos como não-citopatogênicos do BVDV (RADOSTITS et al., 2002).

Muitos trabalhos demonstraram que vacinas inativadas conferem proteção fetal apenas parcial (BRUSCHKE et al., 1999; VOGEL et al., 2001). Já as vacinas atenuadas têm se mostrado mais eficazes em conferir proteção intrauterina contra o BVDV. A proteção da infecção congênita tem sido associada à imunidade em nível celular induzida por essas vacinas (KOVÁCS et 
VIU, M.A.O. et al. Diarreia viral bovina: revisão. PUBVET, Londrina, V. 8, N. 3, Ed. 252, Art. 1670, Fevereiro, 2014.

al., 2003). Além disso, ARENHART et al. (2008) demonstraram que a vacina atenuada conferiu proteção fetal em $89,4 \%$ dos animais analisados.

A vacinação em duas etapas tem sido abordada no uso de vacinas vivas e inativadas para o BVDV (MOENNIG et al., 2005). Segundo FREY et al. (2002), a vacinação primária com uma vacina inativa e revacinação com uma vacina atenuada conferiu $100 \%$ de proteção fetal frente ao genótipo homólogo (BVDV-1) e heterólogo (BVDV-2). Além disso, a primeira vacinação com a vacina inativada reduz ou previne a viremia após a revacinação com a vacina viva, reduzindo ou prevenindo a excreção do vírus vacinal (MOENNIG et al., 2005).

De acordo com COSTA et al. (2006), deve-se vacinar machos e fêmeas a partir dos 3 meses de vida. O reforço deve ser feito após 30 dias, sendo recomendada a revacinação semestral ou anual. Além disso, recomenda-se vacinar os bovinos em fase de reprodução pelo menos um mês antes do começo da estação de monta.

Dentre as vacinas utilizadas encontra-se a Supravac $10^{\circledR}$ (fabricada pela Vencofarma), indicada contra a rinotraqueíte infecciosa, diarreia viral bovina, vírus respiratório sincicial, parainfluenza, leptospiroses e pasteurelose bovinas, devendo ser conservada em temperatura de $2^{\circ} \mathrm{C}$ a $8^{\circ} \mathrm{C}$, até $\mathrm{O}$ momento da aplicação. De acordo com o fabricante deve ser administrada a dose de $5 \mathrm{~mL}$ via subcutânea em animais primovacinados, repetindo-se a dose após 30 dias. Ainda deve-se revacinar os animais semestralmente em dose única. A primeira dose em bezerros deve ser feita aos 4 meses. A imunidade se efetivará 21 dias após a última revacinação.

A vacina IBR/BVD ${ }^{\circledR}$ (fabricada pela Hertape Calier) compõe-se do vírus da rinotraqueíte infecciosa bovina/vulvovaginite pustular infecciosa (IBR/ IPV) e vírus da diarreia viral bovina (BVDV-NADL e BVDV-Nova Iorque). O fabricante recomenda a vacinação de bovinos sadios a partir dos seis meses de idade, devendo-se aplicar, via subcutânea, $5 \mathrm{~mL}$ da vacina e 28 dias após realizar uma $2^{a}$ dose de $5 \mathrm{~mL}$. Então deve-se proceder a revacinação desses 
VIU, M.A.O. et al. Diarreia viral bovina: revisão. PUBVET, Londrina, V. 8, N. 3, Ed. 252, Art. 1670, Fevereiro, 2014.

animais aos 18 meses ou antes da cobertura, revacinando anualmente, independentemente da massa corpórea ou sexo do animal.

\section{CONSIDERAÇÕES FINAIS}

Assim como outras doenças da esfera reprodutiva a BVD representa grandes perdas econômicas, visto que falhas na reprodução podem ser ocasionadas por meio da infecção primária do BVDV, que pode alcançar o trato reprodutivo da fêmea.

Uma vez que rebanhos bovinos brasileiros demonstram um percentual expressivo de ocorrência da mesma, torna-se indispensável que os criadores de gado acatem as medidas de controle e erradicação contra a doença, as quais deverão ser realizadas por um profissional responsável pela sanidade do plantel. Dentre essas medidas, a vacinação de todo o rebanho apresenta-se como etapa importante na redução ou prevenção da viremia nos animais.

Além disso, apesar de não ser uma zoonose, ressalta-se que a doença deve ser tratada como outras de grande relevância, como, por exemplo, a Brucelose, servindo de alerta para que os produtores adotem a vacinação do rebanho com seriedade e responsabilidade.

\section{REFERÊNCIAS}

ARENHART, S.; SILVA, L. F.; HENZEL, A.; FERREIRA, R.; WEIBLEN, R.; FLORES, E. F. Proteção fetal contra o vírus da diarréia viral bovina (BVDV) em vacas prenhes previamente imunizadas com uma vacina experimental atenuada. Pesquisa Veterinária Brasileira, Rio de Janeiro, v. 28, n. 10, p. 461-470, 2008.

BIELANSKI, A. ALGIRE, J. LALONDE, A. Transmission of bovine viral diarrhea virus (BVDV) via in vitro-fertilized embryos to recipients, but not to their offspring. Theriogenology, Stoneham, v. 71, n. 3, p. 499-508, 2009.

BRITO, W. M. E. D.; ALFAIA, B. T.; CAIXETA, S. P. M. B.; RIBEIRO,A. C. C.; MIRANDA, T. M. T.; BARBOSA, A. C. V. C.; BARTHASSON, D. L. B.; LINHARES, D. C.; FARIA, B. O. Prevalência da infecção pelo vírus da diarréia viral bovina (BVDV) no estado de Goiás, Brasil. Revista de Patologia Tropical, Goiânia, v. 39, n.1, p. 7-19, 2010. 
BROCK, K. V. Strategies for the control and prevention of bovine viral diarrhea virus. Veterinary Clinics North America: Food Animal Practice, Philadelphia, v. 20, n. 1, p. 171$180,2004$.

BRUSCHKE, C. J. M.; OIRSCHOT J. T. V.; RIJN, P. A. V. An experimental multivalent bovine virus diarrhea virus E2 subunit vaccine and two experimental conventionally inactivated vaccines induce partial fetal protection in sheep. Vaccine, Kidlinton, v.17, n.15-16, p.1983$1991,1999$.

CANAL, C. W.; STRASSER M.; HERTIG, C.; MASUdA, A. E.; PETERHANS, E. Detection of antibodies to bovine viral diarrhea virus (BVDV) and characterization of genomes of BVDV from Brazil. Veterinary Microbiology, Amsterdam, v. 63, n. 2-4, p. 85-97, 1998.

CANÁRIO, R.; SIMÕES, J.; MONTEIRO, M. H.; MIRA, J. C. Diarreia Viral Bovina. Uma afecção multifacetada. [Revista online]. 2009, v.1, n. 2 (capturado em 29 nov. 2011.) p.288. Disponível em http://www.veterinaria.com.pt/media//DIR_27001/VPC-I-2-e6.pdf: ISSN 1647-3019.

CARTER, G. R. A. Concise review of veterinary virology. Ithaca NY: International Veterinary Information Service, 2004.

COSTA, M. J. R. P.; TOLEDO, L. M.; SCHMIDEK, A. Boas práticas de vacinação. Jaboticabal: FUNEP. 2006, $32 \mathrm{p}$.

DIAS, F. D.; SAMARA, S. I. Deteç̧ão de anticorpos contra o vírus da diarréia viral bovina no soro sangüíneo, no leite individual e no leite de conjunto em tanque de expansão de rebanhos não vacinados. Brazilian Journal of Veterinary Research and Animal Science, São Paulo, v. 40, n. 3, p. 161-168, 2003.

DUBOVI, E. J. Impact of bovine diarrhea virus on reproductive performance in cattle. Veterinary Clinic of North America: Food Animal Practice, Philadelphia, v.10, p. 503-514, 1994.

EVERMANN, J.; BARRINGTON, G. Clinical Features. In: Goyal SM, Ridpath JF. Bovine Viral Diarrhea Virus: Diagnosis, Management and Control. $1^{\mathrm{a}}$ ed. Oxford, UK: Blackwell Publishing, 2005, p. 105-119.

FEED \& FOOD. Primeira vacina contra abortos IBR e BVD. Revista Feed \& Food. 2012. Disponível em: http://www.feedfood.com.br/primeira-vacina-contra-abortos-por-ibr-e-bvd/. Acessado em 10/02/2013.

FINGER, P. F.; SIEDLER, B.; MUNHOZ, L.; JOHANN, J.M.; CAETANO, C.; VILELA, C. O.; VARGAS; VIDOR, T. Prevalência De Infecção Pelo Vírus Da Diarréia Viral Bovina (Bvd) Em Rebanhos Bovinos Do Estado Do Rio Grande Do Sul. XVI Congresso de Iniciação Científica, Anais... 2007.

FLORES, E. F.; Weiblen, R.; VOGEL, F. S. F.; ROEHE, P. M.; ALFIERI, A. A.; PITUCO, E. M. A infecção pelo Vírus da Diarréia Viral Bovina (BVDV) no Brasil: histórico, situação atual e perspectivas. Pesquisa Veterinária Brasileira, Rio de Janeiro, v.25, n.3, p.125-134, 2005.

FORTUNATO, M.; GUEREIRO, D. S.; STILWELL, G. Neospora caninum como causa de aborto bovino em explorações leiteiras. Revista Vaca Leiteira, Lisboa, v. 18, n. 111, p. 64-68, 2010. 
FREY, H. R.; EICKEN, K.; GRUMMER, B.; KENKLIES, S.; OGUZOGLU, T. C.; MOENNIG, V. Foetal protection against bovine virus diarrhea virus after two-step vaccination. Journal of Veterinary Medicine, Berlin, v.49, n.10, p.489-493, 2002.

FULTON, R. W. Vaccines. In: GOYAL, S. M.; RIDPATH, J. F. Bovine Viral Diarrhea Virus: Diagnosis, Management and Control. $1^{a}$ ed. Oxford, UK: Blackwell Publishing, 2005, p. 209-222.

GIL, L.H.V.G. Sequenciamento, análise filogenética e caracterização de polipeptídeos não-estruturais de amostras do vírus da Diarreia Viral Bovina (BVDV). Santa Maria, 1998, 69p. Tese (Mestrado em Medicina Veterinária) - Universidade Federal de Santa Maria.

GOENS, S. D. The evolution of bovine viral diarrheia: a review. Canadian Veterinary Journal, Ottawa, v. 43, n. 12, p. 946-954, 2002.

GONDIM, A.C.L.O. Diarreia Viral Bovina. 2006. Monografia. (Curso de Pós-Graduação "Latu Sensu" em Produção e Reprodução de Bovinos) - Universidade Castelo Branco. Brasília, Brasil.

GUNN, G. J.; STOTT, A. W.; HUMPHRY, R. W. Modelling and costing BVD outbreaks in beef herds. The Veterinary Journal, London, v.167, n. 2, p. 143-149, 2004.

GROOMS, D.; BAKER, J. C.; AMES, T. R. Doenças causadas pelo vírus da diarreia viral bovina. In: SMITH BP. Medicina Interna de Grandes Animais. 3a ed., São Paulo: Manole, 2006, p.707-714.

GROOMS, D. L. Reproductive losses caused by bovine viral diarrhea virus and leptospirosis. Theriogenology, Stoneham, v. 149, n. 66, p. 624-628. 2006.

HIRSCH, C.; FIGUEIREDO, H. C. P. Diarreia bovina a vírus/ doenças das mucosas e rinotraqueíte infecciosa bovina. In: Doenças transmissíveis na Reprodução de Bovinos. Lavras: UFLA/FAEPE, 2006, 66p.

HIRSH, D. C.; ZEE, Y. C. Microbiologia Veterinária. Rio de Janeiro: Editora Guanabara Koogan, 2003. p. 360-361.

HOUE, H. Epidemiological features and economical importance of bovine virus diarrhea virus (BVDV) infections. Veterinary Microbiology, Amsterdam, v. 64, n. 1-3, p.89-107, 1999.

KAHN, C.M. Manual Merck de Veterinária. 6a ed. Barcelona, España: Editorial Océano, 2007, p.215-218.

KELLING, C.L. Evolution of bovine viral diarrhea virus vaccines. Veterinary Clinics of North America: Food Animal pratice, Philadelphia, v.20, n. 1, p.115-129, 2004.

KOVÁCS, F.; MAGYAR, T.; RINEHART, C.; ELBERS, K.; SCHLESINGER, K.; OHNESORGE, W.C. The live attenuated ovine viral diarrhea virus components of a multivalent vaccine confer protection against fetal protection. Veterinary Microbiology, Amsterdam, v.96, n.2, p.117$131,2003$.

KREY, T.; HIMMELREICH, A.; HEIMANN, M.; MENGE, C.; THIEL, H. J.; MAURER, K.; RUMENAPF, T. Function od bovine CD46 as a cellular receptor for bovine viral diarrhea vírus is determined by complement control protein 1 . Journal of Virology, Washington, v. $80, n$. 8 , p. 3912-3922, 2006. 
LAZZARI, F. C.; BARTHOLOMEI, L. F. Diarréia Viral Bovina. Revista Científica Eletrônica de Medicina Veterinária, Garça, n. 10, p. 1-4, 2008.

LEMOS, R. A. A. Diarreia viral bovina. In: PRINCIPAIS ENFERMIDADES DE BOVINOS DE CORTE DO MATO GROSSO DO SUL: RECONHECIMENTO E DIAGNÓSTICO. Campo Grande. Palestras... Campo Grande: Universidade Federal do Mato Grosso do Sul, p. 226-258, 1998.

LINDBERG, A.; BROWNLIE, J.; GUNN, G. J.; HOUE, H.; MOENNIG, V.; SAATKAMP, H.W.; SANDVIK T, VALLE, P.S. The control of bovine viral diarrhea virus in Europe: today and in the future. Revue scientifique et technique, Neuilly, v.25, n.3, p.961-979, 2006.

MARQUES, D. C. Criação de bovinos. 7. ed. Belo Horizonte: Consultoria Veterinária e Publicações, 2003. p. 517-519.

MENDES, M. B.; BITTAR, J. F. F.; PEREIRA, W. B. A.; ARDUINO,G. G. C.; BITTAR, E. R. PANETTO, C.; SANTOS, J. P. Determinação da prevalência das principais doenças da reprodução no rebanho bovino da região de Uberaba-MG. Ciência Animal Brasileira Suplemento 1, Anais... VIII Congresso Brasileiro de Buiatria. 2009.

MOCKELIUNIENE, V.; SALOMSKAS, A.; MOCKELIUNAS, R.; PETKEVICIUS, S. Prevalence and epidemiological features of bovine viral diarrhoea virus infection in Lithuania. Veterinary Microbiology, Amsterdam, v.99, n.1, p.51-57, 2004.

MOENNIG, V.; EICKEN, K.; FLEBBE, U.; FREY, H. R.; GRUMMER, B.; HAAS, L.; GREISERWILKE, I.; LIESS, B. Implementation of two-step vaccination in control of bovine viral diarrhoea. Preventive Veterinary Medicine, Amsterdam, v.72, n.1-2, p.109-114, 2005.

NELSON, G.; MARCONI, P. PERIOLO, O.; TORRE, J. L.; ALVAREZ, M. A. Immunocompetent truncated E2 glycoprotein of bovine viral diarrhea vírus (BVDV) expressed in Nicotiana tabacum plants: A candidate antigen for new generation of veterinary vaccines. Vaccine, v.30, n.30, p. 4499-4504, 2012.

NOIVA, R. M. G. Utilização de imunohistoquímica e AgELISA para detecção de portadores do virus da diarreia viral bovina em bovinos de engorda. 2010. 108p. Dissertação de mestrado. Universidade Técnica de Lisboa, Faculdade de Medicina Veterinária.

OIE. World Organisation for Animal Health. Infectious Bovine Rhinotracheitis/Infectious Pustular Vulvovaginitis. In: Manual of diagnostic tests and vaccines for terrestrial animals. Paris, France: OIE; 2008. p. 752-67.

OLIVEIRA, P. M. A. Manual Merck de Veterinária. 8.ed., São Paulo: Roca, 2001. 1861p.

PERDRIZET, J. A.; REBHUN, W. C.; DUBOVI, E. J. Bovine viral diarrhoea: clinical syndromes in dairy herds. Cornell Veterinarian, Ithaca, v. 77, p. 46-74, 1987.

PETERHANS, E.; BACHOFEN, C.; STALDER, H. Cytopathic bovine diral diarrhea viruses (BVDV): emerging pestiviruses doomed to extinction. Veterinary Research. Les Ulis, v.41, n. 6, p. 4144, 2010.

POLLETO, R.; KREUT, L. C.; GONZALES, J. C. Prevalência de tuberculose, brucelose e infecções víricas em bovinos leiteiros do município de Passo Fundo, RS. Ciência Rural, Santa Maria, v. 34, n. 2, p. 595-598, 2004.

POTGIETER, L. N. D. Bovine Viral diarrhea and mucosal disease: In: Infectious Diseases of Livestock. 2 ed. Oxford University Press Soulthern África, Cape Town. 2004, v. 2, p. 946-969. 
QUINCOZES, C.G. Prevalência e fatores de risco associados às infecções pelos herpesvírus bovino tipo 1 e 5 (BHV-1 e 5) e pelo vírus da diarréia víral bovina (BVDV) nos rebanhos dos municípios de Santa Vitória do Palmar e Chuí. 2007. 117f. Dissertação (Mestrado em Ciências) - Universidade Federal de Pelotas, Rio Grande do Sul.

RADOSTITS, O. M.; GAY, C. C.; BLOOD, D. C.; HINCHCLIFF, K. W. Clínica Veterinária: um tratado de doenças dos bovinos, ovinos, suínos, caprinos e equinos. 9. ed. Rio de Janeiro: Editora Guanabra Koogan, 2002, p. 974-992.

RADOSTITS, O. M.; GAY, C. C.; BLOOD, D. C.; HINCHCLIFF, K. W. Veterinary medicine: A textbook of the diseases of cattle, horses, sheep, pigs and goats. 10.ed. Philadelphia: Saunders-Elsevier, 2007, 2156 p.

RIDPATH, J. F. Bovine Viral Diarrhea. Virus: Global Status. Veterinary Clinics North America: Food Animal Practice, Philadelphia, v. 26, p. 105-121, 2010.

SILVA, T. M. A.; OLIVEIRA, R. G.; MOL, J. P. S.; XAVIER, M. N.; PAIXÃO, T. A.; CORTEZ, A.; HEINEMANN, M. B.; RICHTZENHAIN, L. J.; LAGE, A. P.; SANTOS, R. L. Diagnóstico etiológico de aborto infeccioso bovino por PCR. Ciência Rural, Santa Maria, v.39, n. 9, p.2563-2570, 2009.

THOMPSON, J. A.; LEITE, R. M. H.; GONÇALVES, V. S.; LEITE, R. C.; BANDEIRA, D. A.; HERRMANN, G. P.; MOREIRA, E. C.; PRADO, P. E.; LOBATO, Z. I.; DE BRITO, C. P.; LAGE, A. $P$. Spatial hierarchical variances and age covariance for seroprevalence to Leptospira interrogans serovar hardjo, BoHV-1 and BVDV for cattle in the State of Paraíba, Brazil. Preventive Veterinary Medicine, Amsterdam, v. 76, n, 3-4, p. 290-301, 2006.

TREMBLAY, R. Transmission of bovine viral diarrhea vírus. In: Symposium on bovine viral diarrhea vírus. Veterinary Medicine, Lenexa, v.91, n. 9, p. 858-866, 1996.

VOGEL, F. S. F.; SCHERER, C. F. C.; FLORES, E. F.; WEIBLEN, R.; LIMA, M.; KUNRATH C. F. Resposta sorológica e avaliação de proteção fetal em ovelhas prenhes vacinadas contra os vírus da diarreia viral bovina (BVDV). Ciência Rural, Santa Maria, v.31, n.5, p.831-838, 2001.

XUE, F.; ZHU, Y. M.; LI, J.; ZHU, L. C.; REN, X. G.; FENG, J. K.; SHI, H. F.; GAO, Y. R. Genotyping of bovine viral diarrheia viruses from cattle in China between 2005 and 2008. Veterinary Microobiology, Amsterdam, v. 143, n. 2-3, p. 379-383, 2008. 
VIU, M.A.O. et al. Diarreia viral bovina: revisão. PUBVET, Londrina, V. 8, N. 3, Ed. 252, Art. 1670, Fevereiro, 2014.

\section{ANEXO 1}

QUADRO 1 - Relação de doenças virais com sinais clínicos semelhantes aos da BVD para diagnóstico diferencial da BVD

\begin{tabular}{|c|c|c|c|}
\hline Doença & Epidemiologia & Achados Clínicos & Patologia Clínica \\
\hline $\begin{array}{l}\text { Catarro maligno } \\
\text { de bovinos }\end{array}$ & $\begin{array}{c}\text { Esporádico. } \\
\text { Animais adultos e } \\
\text { jovens }\end{array}$ & $\begin{array}{c}\text { Estomatite erosiva } \\
\text { acentuada difusa; } \\
\text { Febre alta; Conjuntivite } \\
\text { acentuada; Opacidade } \\
\text { cornoescleral; } \\
\text { Hematúria; Linfonodos } \\
\text { enfartados; Diarreia; } \\
\text { Encefalite terminal }\end{array}$ & $\begin{array}{l}\text { Leucopenia e } \\
\text { neutropenia; } \\
\text { Leucocitose } \\
\text { tardiamente }\end{array}$ \\
\hline Febre Aftosa & $\begin{array}{l}\text { Alta morbidade; } \\
\text { baixa mortalidade }\end{array}$ & $\begin{array}{c}\text { Febre alta; Sialorreia; } \\
\text { Vesículas na boca, nas } \\
\text { tetas; Morte na forma } \\
\text { miocárdica }\end{array}$ & $\begin{array}{c}\text { Testes de } \\
\text { transmissão no } \\
\text { animal; Sorologia } \\
\text { rápida }\end{array}$ \\
\hline Peste bovina & $\begin{array}{l}\text { Bovinos jovens e } \\
\text { adultos; Surtos; } \\
\text { Rápida } \\
\text { disseminação; 90\% } \\
\text { mortalidade }\end{array}$ & $\begin{array}{c}\text { Estomatite erosiva } \\
\text { acentuada; Saliva } \\
\text { corada de sangue; } \\
\text { Diarreia intensa e } \\
\text { disenteria }\end{array}$ & $\begin{array}{l}\text { Leucopenia } \\
\text { acentuada; } \\
\text { Linfopenia; } \\
\text { Cariorrexe }\end{array}$ \\
\hline $\begin{array}{c}\text { Estomatite } \\
\text { vesicular }\end{array}$ & $\begin{array}{l}\text { Morbidade e } \\
\text { mortalidade } \\
\text { variáveis }\end{array}$ & $\begin{array}{c}\text { Febre moderada; } \\
\text { Anorexia; Vesículas na } \\
\text { cavidade bucal }\end{array}$ & $\begin{array}{c}\text { Testes de } \\
\text { transmissão no } \\
\text { animal; Sorologia } \\
\text { rápida }\end{array}$ \\
\hline Língua Azul & $\begin{array}{c}\text { Doença clínica não } \\
\text { comum nos } \\
\text { bovinos }\end{array}$ & $\begin{array}{c}\text { Febre; Rigidez; } \\
\text { Laminite; Coronite; } \\
\text { Lesões erosivas na } \\
\text { cavidade oral; Edema } \\
\text { dos lábios; Salivação; } \\
\text { Corrimento nasal e } \\
\text { ocular }\end{array}$ & $\begin{array}{c}\text { Testes de } \\
\text { transmissão no } \\
\text { animal; Sorologia } \\
\text { rápida }\end{array}$ \\
\hline $\begin{array}{c}\text { Estomatite } \\
\text { papular bovina }\end{array}$ & $\begin{array}{l}\text { Bovinos jovens ( } 2 \\
\text { semanas a } 2 \\
\text { anos); } 100 \% \\
\text { morbidade; }\end{array}$ & $\begin{array}{c}\text { Pápulas redondas } \\
\text { vermelho-escuras } \\
\text { elevadas no focinho e } \\
\text { cavidade bucal }\end{array}$ & - \\
\hline $\begin{array}{l}\text { Disenteria } \\
\text { invernal dos } \\
\text { bovinos }\end{array}$ & $\begin{array}{l}\text { Rebanho leiteiro } \\
\text { confinado; } \\
\text { Inverno; Surto } \\
\text { explosivo; } \\
\text { Morbidade } 100 \%\end{array}$ & $\begin{array}{c}\text { Diarreia aquosa } \\
\text { profunda aguda e } \\
\text { disenteria; Febre } \\
\text { moderada; Inapetência } \\
\text { e queda na produção } \\
\text { de leite }\end{array}$ & - \\
\hline
\end{tabular}

Fonte: Adaptado de RADOSTITS et al. (2002). 
VIU, M.A.O. et al. Diarreia viral bovina: revisão. PUBVET, Londrina, V. 8, N. 3, Ed. 252, Art. 1670, Fevereiro, 2014.

ANEXO 2
QUADRO 2 - Relação de doenças bacterianas com sinais clínicos semelhantes aos da
BVD para diagnóstico diferencial da BVD
\begin{tabular}{|c|c|c|l|}
\hline Doença & Epidemiologia & Achados Clínicos & Patologia Clínica \\
\hline $\begin{array}{c}\text { Estomatite } \\
\text { necrótica }\end{array}$ & $\begin{array}{c}\text { Bezerros jovens em } \\
\text { condições sujas e } \\
\text { pastagens secas }\end{array}$ & $\begin{array}{c}\text { Grandes úlceras } \\
\text { necróticas profundas } \\
\text { de odor desagradável } \\
\text { na língua }\end{array}$ & Esofagite necrótica \\
\hline $\begin{array}{c}\text { Salmonelose } \\
\text { Todas idades; } \\
\text { Surtos; Mortalidade } \\
\text { alta }\end{array}$ & $\begin{array}{c}\text { Forma aguda: febre } \\
\text { alta, diarreia, } \\
\text { disenteria, dor } \\
\text { abdominal; Forma } \\
\text { subaguda e crônica: } \\
\text { também ocorre diarreia }\end{array}$ & $\begin{array}{l}\text { Leucopenia; } \\
\text { Neutropenia; } \\
\text { Enterite } \\
\text { fibrinoemorrágica }\end{array}$ \\
\hline $\begin{array}{c}\text { Doença de } \\
\text { Johne }\end{array}$ & $\begin{array}{c}\text { Baixa morbidade; } \\
\text { Longo curso }\end{array}$ & $\begin{array}{c}\text { Diarreianica; Perda } \\
\text { de peso; Temperatura } \\
\text { e apetite normais }\end{array}$ & $\begin{array}{l}\text { Teste } \\
\text { Cultura sorológico; } \\
\text { Enterite }\end{array}$ \\
\hline
\end{tabular}

Fonte: Adaptado de RADOSTITS et al. (2002).

\section{ANEXO 3}

QUADRO 3 - Relação de doenças causadas por protozoários com sinais clínicos semelhantes aos da BVD para diagnóstico diferencial da BVD

\begin{tabular}{|c|c|c|c|}
\hline Doença & Epidemiologia & Achados Clínicos & Patologia Clínica \\
\hline Ostertagíase & $\begin{array}{c}\text { Bovinos jovens (6 } \\
\text { meses a 2 anos) }\end{array}$ & $\begin{array}{c}\text { Diarreia persistente } \\
\text { sem odor; Apetite } \\
\text { diminuído; Perda de } \\
\text { peso }\end{array}$ & $\begin{array}{l}\text { Contagem de ovo } \\
\text { pesado, nível de } \\
\text { pepsinogênio } \\
\text { plasmático }\end{array}$ \\
\hline Coccidiose & $\begin{array}{c}\text { Disenteria subaguda; } \\
\text { Febre moderada; } \\
\text { Buperlotados no } \\
\text { rebanho }\end{array}$ & $\begin{array}{c}\text { Apetite e hidratação } \\
\text { normais; 20\% dos } \\
\text { animais desenvolvem } \\
\text { sinais nervosos e } \\
\text { morrem }\end{array}$ & $\begin{array}{l}\text { Fezes para oocistos; } \\
\text { hecite e colite }\end{array}$ \\
& \multicolumn{3}{|c|}{} \\
\hline
\end{tabular}

Fonte: Adaptado de RADOSTITS et al. (2002). 
VIU, M.A.O. et al. Diarreia viral bovina: revisão. PUBVET, Londrina, V. 8, N. 3, Ed. 252, Art. 1670, Fevereiro, 2014.

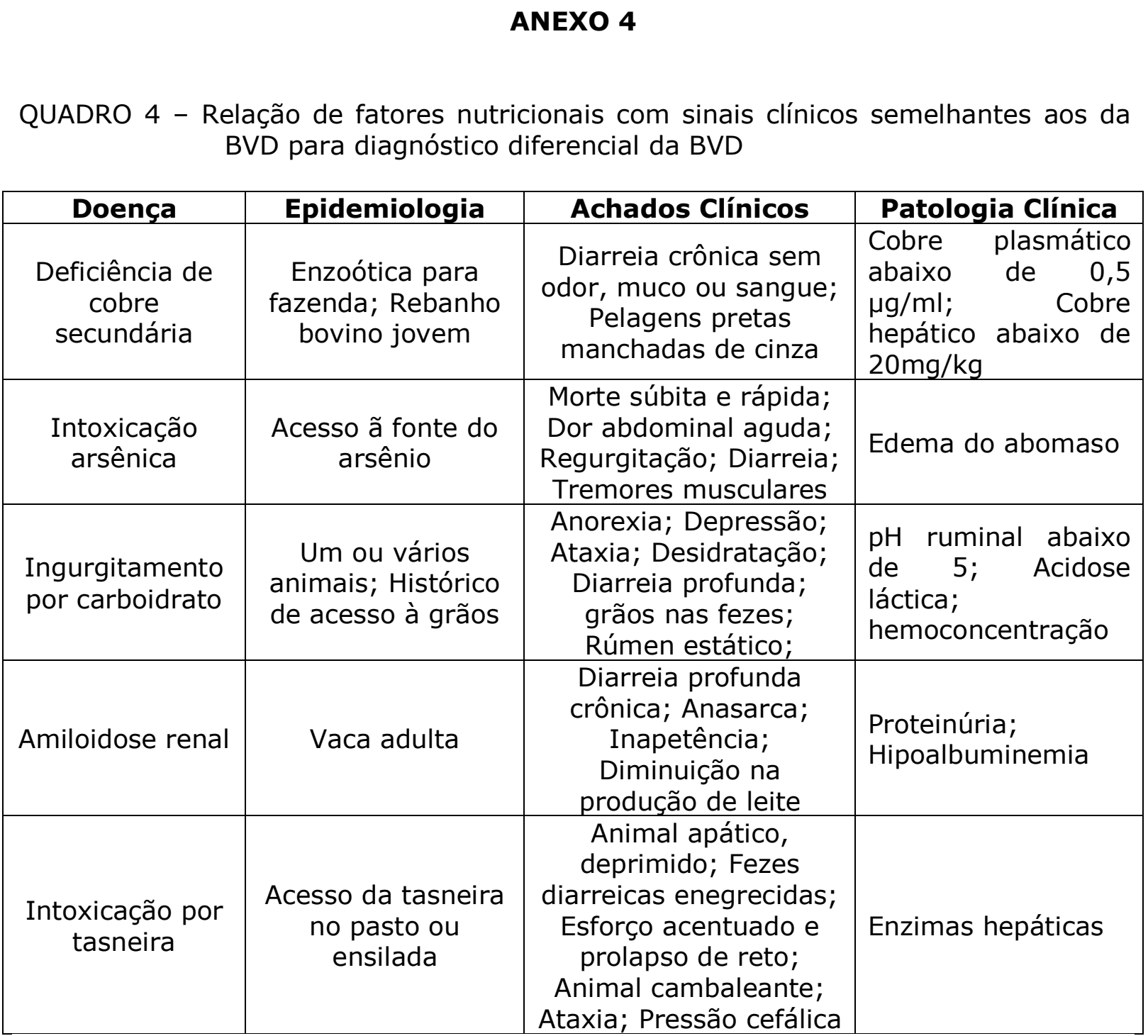

Fonte: Adaptado de RADOSTITS et al. (2002). 
VIU, M.A.O. et al. Diarreia viral bovina: revisão. PUBVET, Londrina, V. 8, N. 3, Ed. 252 , Art. 1670, Fevereiro, 2014.

\section{ANEXO 5}

QUADRO 5 - Relação das causas de abortamento em bovinos para diagnóstico diferencial da BVD

\begin{tabular}{|c|c|c|}
\hline Doença & Período de abortamento & Índice de abortamento \\
\hline BVD & $<3^{\circ}$ trimestre & Esporádico \\
\hline Brucelose & +6 meses & Alto, até $90 \%$ \\
\hline Tricomoníase & $2-4$ meses & Moderado, 5-30\% \\
\hline Neosporose & $\begin{array}{c}\text { 3-8 meses (média de } 5,5 \\
\text { meses) }\end{array}$ & Esporádico ou surtos (20-40\%) \\
\hline Vibriose & 5-6 meses & Baixo, 5-20\% \\
\hline Leptospirose & Tardio, + de 6 meses & $25-30 \%$ \\
\hline Micoses & 3-7 meses & $6-7 \%$ \\
\hline Listeriose & Aproximadamente 7 meses & Baixo \\
\hline IBR & Tardio, 6 meses & $25-50 \%$ \\
\hline $\begin{array}{l}\text { Aborto Viral } \\
\text { Epizoótico }\end{array}$ & 6-8 meses & Alto, $30-40 \%$ \\
\hline Micoplasmose & 30 trimestre & Esporádico \\
\hline Clamidofilose & +7 meses & Esporádico \\
\hline Língua Azul & Variável & Esporádico \\
\hline $\begin{array}{c}\text { Bactérias } \\
\text { oportunistas }\end{array}$ & 20 Trimestre & Esporádico \\
\hline Salmonelose & 4-9 meses & Esporádico, surtos \\
\hline
\end{tabular}

Fonte: Adaptado de RADOSTITS et al. (2002) e FORTUNATO et al. (2010). 